\title{
Perception of and adaptation to rectal isobaric distension in patients with faecal incontinence
}

\author{
L Siproudhis, E Bellissant, F Juguet, H Allain, J-F Bretagne, M Gosselin
}

\begin{abstract}
Background-Perception of, and adaptation of the rectum to, distension probably play an important role in the maintenance of continence, but perception studies in faecal incontinence provide controversial conclusions possibly related to methodological biases. In order to better understand perception disorders, the aim of this study was to analyse anorectal adaptation to rectal isobaric distension in subjects with incontinence.

Patients/Methods-Between June 95 and December 97, 97 consecutive patients (nine men and 88 women, mean (SEM) age 55 (1) years) suffering from incontinence were evaluated and compared with 15 healthy volunteers (four men and 11 women, mean age 48 (3) years). The patients were classified into three groups according to their perception status to rectal isobaric distensions (impaired, 22; normal, 61; enhanced, 14). Anal and rectal adaptations to increasing rectal pressure were analysed using a model of rectal isobaric distension.
\end{abstract}

Results-The four groups did not differ with respect to age, parity, or sex ratio. Magnitude of incontinence, prevalence of pelvic disorders, and sphincter defects were similar in the incontinent groups. When compared with healthy controls, anal pressure and rectal adaptation to distension were decreased in incontinent patients. When compared with incontinent patients with normal perception, patients with enhanced perception experienced similar rectal adaptation but had reduced anal pressure. In contrast, patients with impaired perception showed considerably decreased rectal adaptation but had similar anal pressure.

Conclusion-Abnormal sensations during rectal distension are observed in one third of subjects suffering from incontinence. These abnormalities may reflect hyperreactivity or neuropathological damage of the rectal wall.

(Gut 1999;44:687-692)

Keywords: faecal; incontinence; rectum; barostat; perception; distension

E Bellissant

F Juguet

H Allain

J-F Bretagne

M Gosselin

Correspondence to:

Dr Siproudhis.

Accepted for publication 17 December 1998 culprit in faecal incontinence. However, proximal sensation and adaptation of the rectum to distension probably play an important role in this disease for several reasons. Firstly, external anal sphincter responses to rectal stimulation
Anal dysfunction classically remains the are crucial in preserving continence and they are closely related to rectal sensory function. ${ }^{1}$ Secondly, patients with neurogenic incontinence have impaired perception of distension and electrical stimulation. ${ }^{2}$ Finally, biofeedback techniques modifying rectal balloon sensitivity have been shown to improve the condition of patients with faecal incontinence. ${ }^{3}$ Although some studies have shown impaired rectal sensation in faecal incontinence, ${ }^{14-6}$ others have found either no abnormality $^{7}$ or enhanced perception ${ }^{8}$; these apparent discrepancies may be related to methodological problems raised by isovolumic stimulation. Indeed, analysis of perception and compliance of the rectum by isovolumic distension models is inaccurate because these models hypothesise that $(a)$ the rectum can be modelled as a closed cylinder, $(b)$ the rectal size does not influence measured rectal compliance, and (c) the rectum is mechanically passive. ${ }^{9}{ }^{10}$ Moreover, relative variations in pressure thresholds for eliciting rectal sensation and rectoanal inhibitory reflex are lower than corresponding threshold volumes. ${ }^{11}$ Finally, volume is not linearly related to rectal diameter or to balloon pressure because air is compressible and because small variations in bag shape and dimensions may affect the pressure-volume relation. For all these reasons, isobaric stimulation is actually preferable to isovolumic distension. ${ }^{9}$

Using a model of rectal isobaric distension, the aim of our study was to analyse the anorectal physiology with respect to perception status in faecal incontinence.

\section{Subjects and methods}

STUDY GROUPS

Between June 95 and December 97, 97 consecutive patients (nine men and 88 women; mean (SEM) age 55 (1) years) suffering from symptoms of faecal incontinence to liquid and/or solid stools were enrolled. They were classified into three groups according to their perception status defined in response to rectal isobaric distension (see below): impaired ( $\mathrm{n}=$ $22)$, normal $(n=61)$ or enhanced $(n=14)$ perception. They were compared with 15 healthy volunteers (four men and 11 women; mean age 48 (3) years). Patients were excluded if they were pregnant, had been treated with medications containing cholinergic agents, $\alpha$-adrenergic drugs, or cathartic laxatives during the preceding six months, or had a previous history of pelvic radiation, perineal or anal sphincter reconstruction, or surgery of the rectum. Patients were also excluded if the following abnormalities were encountered: chronic 
diarrhoea, encopresia or fecaloma, severe constipation, rectal or colonic mucosal changes, suspected or proved neurological abnormalities, psychiatric disorders, and diabetes. Healthy volunteers had to have no gastrointestinal symptoms or surgical history of the pelvis.

Each patient answered a standard questionnaire and had a physical examination, anal endosonography, defecography, and anal manometry. The questionnaire focused on the main anorectal complaints and surgical and obstetrical histories. Continence failure within the preceding month was scored on the basis of a 0 to 18 point scale. ${ }^{12}$ Anal endosonography (EUM 20; Olympus Scop Médecine, Rungis, France) was performed to identify defects involving the external and internal sphincters. Defecography was performed to identify rectal prolapse, perineal descent and rectocele, and to analyse rectal emptying. ${ }^{13}$ Rectal prolapse was defined by an intra-anal or exteriorised intussusception of the rectal wall at strain. Perineal descent was quantified by the maximal length that separated the upper anal canal site and the pubococcygeal line during defecation. Anal manometry was performed using a three lumen water perfused catheter assembly to record mean maximum resting pressure at both upper and lower parts and maximal and mean squeeze pressure at the lower part of the anal canal.

PROTOCOL

The protocol of the study had been previously reviewed and approved by the ethics committee of our institution (Comité Consultatif de Protection des Personnes dans la Recherche Biomédicale, Hôtel-Dieu, Rennes, France). Each patient and healthy volunteer was submitted to one session of phasic isobaric distensions of the rectum.

\section{EQUIPMENT}

An electronic barostat was used to stimulate the rectum, and anal manometry was used to evaluate responses at different levels of the anal canal. Distension procedures were performed with a highly compliant polyethylene bag placed within the rectum and connected to the electronic barostat (ABS, Saint Dié, France), as previously described..$^{14}$ Anal canal pressures were monitored using a three lumen water perfused catheter (R3B \& PIP4-4; Mui Scientific, Mississauga, Ontario, Canada) assembly with radially distributed side holes, spaced $0.5 \mathrm{~cm}$ apart for the two proximal holes. Anal pressures were first recorded during resting and voluntary squeezing states. During isobaric distensions of the rectum, rectal and anal pressures were continuously recorded by a computerised motility system (Smartlab Computerised Motility System; Solal-Sandhill, Strasbourg, France).

Phasic distension was performed by rapidly inflating the bag to successive predetermined ascending levels of pressure (from 6 to $31 \mathrm{~mm}$ $\mathrm{Hg}$, with $5 \mathrm{~mm} \mathrm{Hg}$ increments), each level being maintained for 60 seconds and separated from the next by a 60 second rest period at 0 $\mathrm{mm} \mathrm{Hg}$.

VARIABLES INVESTIGATED

In response to the rectal distension protocol, the following variables were monitored.

(1) Anal pressure at both upper and lower parts of the anal canal. Conventionally, the upper part is thought to reflect the manometric activity of the internal anal sphincter and the lower part that of the external anal sphincter. At each pressure step, anal pressure was defined as the mean pressure recorded at the level investigated.

(2) Maximal rectal pressure recorded by the manometric device during each plateau pressure in order to detect the occurrence of rectal contraction.

(3) Maximal rectal volume recorded at the end of each step of preselected pressure.

(4) Volume variation during ascending rectal pressure. It represents the difference between the volume at resting state $(0 \mathrm{ml})$ and the volume measured when the preselected pressure was just reached. As this is a volume variation over the variation of two levels of pressure, it is thought to reflect rectal compliance. ${ }^{15}$

(5) Volume variation at constant rectal pressure, which is a volume variation in response to a stabilised preselected pressure (maximal volume - initial volume). It describes rectal tone (pressure variation $=$ $0 \mathrm{~mm} \mathrm{Hg}$ ) in this phasic isobaric distension model. ${ }^{15}$

(6) Sensation intensity at each pressure step (when rectal pressure was just stabilised) expressed on a six point scale ranging from no sensation to pain. All subjects received standard instructions specifying that score 0 represents no sensation, score 1 a vague perception of mild sensation, score 2 a definite perception of mild sensation, score 3 a vague perception of moderate sensation, score 4 a definite perception of moderate sensation, score 5 discomfort, and score 6 a painful sensation. ${ }^{16}$ Impaired perception was defined as an absence of sensation (score $=0$ ) and an enhanced sensation as discomfort (score $=5$ ) during pressure steps of rectal distension $<21 \mathrm{~mm}$ $\mathrm{Hg}$ because these features were never encountered in healthy volunteers. ${ }^{17}$

\section{STATISTICAL ANALYSIS}

Quantitative variables are expressed as means (SEM), and percentages of variation between groups were calculated. Qualitative variables are expressed as percentages. Distributions of quantitative variables recorded at inclusion were compared between groups using one way analysis of variance followed, in the case of a significant effect, by unpaired $t$ tests. Two way (group, pressure step) repeated measures analysis of variance was performed on the data for anal pressure, rectal pressure, and volume. A group effect highlights the difference in means between studied groups, all pressure steps included. A pressure effect highlights the difference in means between pressure steps, all 
Table 1 Study groups at inclusion. General characteristics and anal pressures obtained using routine manometry

\begin{tabular}{|c|c|c|c|c|}
\hline & \multirow[b]{2}{*}{$\begin{array}{l}\text { Controls } \\
(n=15)\end{array}$} & \multicolumn{3}{|c|}{ Incontinent patients } \\
\hline & & $\begin{array}{l}\text { Impaired } \\
\text { perception } \\
(n=22)\end{array}$ & $\begin{array}{l}\text { Normal } \\
\text { perception } \\
(n=61)\end{array}$ & $\begin{array}{l}\text { Enhanced } \\
\text { perception } \\
(n=14)\end{array}$ \\
\hline \multicolumn{5}{|l|}{ General characteristics } \\
\hline Age (years) & $48(3)$ & $55(4)$ & $55(2)$ & $53(4)$ \\
\hline Parity (number) & $2.2(0.3)$ & $2.1(0.3)$ & $2.6(0.3)$ & $2.0(0.4)$ \\
\hline Male sex & 4 & 1 & 7 & 1 \\
\hline Weekly stool (number) & $6.6(0.6)$ & $8.6(0.9)$ & $10.9(0.9)^{\star} \dagger$ & $6.1(1.3)$ \\
\hline Incontinence score $(0-18)$ & 0.0 & $13.1(0.9)^{\star}$ & $12.4(0.5)^{\star}$ & $10.3(1.2)^{\star}$ \\
\hline Previous surgery (number) & 4 & $15^{\star}$ & $42^{\star}$ & $8^{\star}$ \\
\hline \multicolumn{5}{|l|}{ Anal pressure $(\mathrm{mm} \mathrm{Hg})$} \\
\hline \multicolumn{5}{|l|}{ Upper part } \\
\hline Mean resting & $66.7(7.5)$ & $30.4(3.6)^{\star}$ & $31.6(3.1)^{\star}$ & $23.4(3.5)^{\star}$ \\
\hline \multicolumn{5}{|l|}{ Lower part } \\
\hline Mean resting & $63.0(5.1)$ & $30.0(3.2)^{\star} \dagger$ & $33.6(2.7)^{\star} \dagger$ & $17.8(2.4)^{\star}$ \\
\hline Maximum squeeze & $172.0(11.7)$ & $72.5(8.2)^{\star}$ & $85.8(7.0)^{\star}$ & $69.2(10.3)^{\star}$ \\
\hline Mean squeeze & $119.2(7.3)$ & $53.8(6.7)^{\star}$ & $63.1(5.2)^{\star}$ & $46.2(6.8)^{\star}$ \\
\hline
\end{tabular}

Data are means (SEM) for quantitative variables and effectives (with percentages) for qualitative variables. ${ }^{\star}$ and + indicate significance when the group considered was compared with the control group and the incontinent group with enhanced perception respectively. Past history of previous surgery focused on pelvic and perineal surgical procedures (including episiotomy).

studied groups included. A group $\times$ pressure interaction highlights the fact that differences between groups depend on the level of distending pressure. Thus a variable is significantly different between groups when a significant group effect or a significant group $\times$ pressure interaction is observed. Distributions of qualitative variables recorded at inclusion were compared between groups by the $\chi^{2}$ test. For each analysis, $\mathrm{p}$ values less than 0.05 were considered to be statistically significant.

\section{Results}

POPULATION

Table 1 presents the general characteristics of the study population at inclusion and the anal pressures obtained using routine manometry. The four groups did not differ with respect to age, parity, or sex ratio. Stool frequency was similar between controls and incontinents with impaired or enhanced perception, but it was increased in incontinent subjects with normal perception. As expected, both resting and squeeze pressures were lower in patient groups than in healthy subjects. Moreover, mean resting pressure at the lower part of the anal canal was significantly lower in patients with enhanced perception than in those in the two other incontinent groups. Table 2 shows that rectoperineal disorders were similar for all groups of patients. As assessed by objective tests, the magnitude of incontinence and dyschesia were comparable between groups,

Table 2 Incontinent groups at inclusion: main disorders encountered at evacuation proctography and at anal endosonography

\begin{tabular}{llll}
\hline & $\begin{array}{l}\text { Impaired perception } \\
(n=22)\end{array}$ & $\begin{array}{l}\text { Normal perception } \\
(n=61)\end{array}$ & $\begin{array}{l}\text { Enhanced perception } \\
(n=14)\end{array}$ \\
\hline Rectocele & $6(27 \%)$ & $19(31 \%)$ & $3(21 \%)$ \\
Prolapse & $9(41 \%)$ & $22(36 \%)$ & $8(57 \%)$ \\
Complete rectal emptying & $13(59 \%)$ & $34(56 \%)$ & $8(57 \%)$ \\
Emptying duration (seconds) & $33(5)$ & $32(3)$ & $32(4)$ \\
Barium paste leakage <200 $\mathrm{ml}$ & $10(46 \%)$ & $20(33 \%)$ & $7(50 \%)$ \\
First volume leakage $(\mathrm{ml})$ & $135(11)$ & $126(10)$ & $173(5)^{\star}$ \\
Perineal descent (mm) & $70(4)$ & $63(3)$ & $73(5)$ \\
External sphincter defect & $14(64 \%)$ & $32(53 \%)$ & $5(36 \%)$ \\
Internal sphincter defect & $10(46 \%)$ & $28(46 \%)$ & $10(71 \%)$ \\
\hline
\end{tabular}

Data are means (SEM) for quantitative variables and effectives (with percentages) for qualitative variables. * indicates significance when incontinents with enhanced rectal perception are compared with each other group. and sphincter defects occurred similarly in all incontinent groups.

\section{MANOMETRIC RECORDINGS (RECTAL AND ANAL} PRESSURES)

Figure 1 shows rectal and anal responses to rectal isobaric distension as a function of the pressure of distension in the four groups.

Increasing pressure of distension significantly modified manometric recordings at both rectal and upper anal levels (table 3). Such an effect was not encountered in the lower part of the anal canal. Increasing rectal distension increased maximal rectal pressure $(p=0.001)$, lowered anal pressure in the upper part of the anal canal $(p=0.001)$, and had no effect on anal pressure in the lower part of the anal canal $(\mathrm{p}=0.404)$.

All pressure steps of rectal distension considered, the effects on maximal rectal pressure and anal pressure in the upper part of the anal canal were not significantly different between groups ( $p=0.16$ and $p=0.08$ respectively). However, there were some significant differences between groups at some pressures of rectal distension (pressure $\times$ group interaction).

A group effect was observed in the lower part of the anal canal at each level of distending pressure (no pressure $\times$ group interaction).

As compared with healthy controls, rectal pressures were significantly decreased in incontinents with normal perception (group effect, $\mathrm{p}$ $=0.035 ;$ pressure $\times$ group interaction, $\mathrm{p}<0.001$ ) (table 3).

As compared with healthy controls, anal pressures in the upper part were significantly lower in incontinents with impaired or enhanced rectal perception (group effects, $\mathrm{p}=$ 0.04 and 0.004 ; pressure $\times$ group interaction: $p$ $=0.003$ and $\mathrm{p}<0.001$ respectively) (table 3 ). The group effects were mainly observed when distending rectal pressure was $16 \mathrm{~mm} \mathrm{Hg}$ or less.

Anal pressure in the lower part of the anal canal was significantly decreased in incontinents, irrespective of the step of distending pressure (group effects, $\mathrm{p}<0.001$ ). At this level, pressures were significantly lowered in patients with enhanced perception compared with the other two incontinent groups ( $v$ normal perception, $\mathrm{p}=0.01 ; v$ impaired perception, $\mathrm{p}$ $=0.03$ ).

BAROSTAT RECORDINGS (RECTAL ADAPTATION) Figure 2 shows rectal adaptation to isobaric distension as a function of the pressure of distension in the four groups (expressed as maximal rectal volume, volume variation during increasing pressure, and volume variation at constant pressure). Increasing pressure of distension significantly increased all recorded rectal volumes $(\mathrm{p}<0.001$ for each variable).

Differences between groups were also observed for all recorded rectal volumes (group effects, $p<0.001$ for each variable). These differences did not depend on the pressure of distension (no significant pressure $\times$ group interaction whatever the variable considered). As compared with healthy subjects, the following variables 

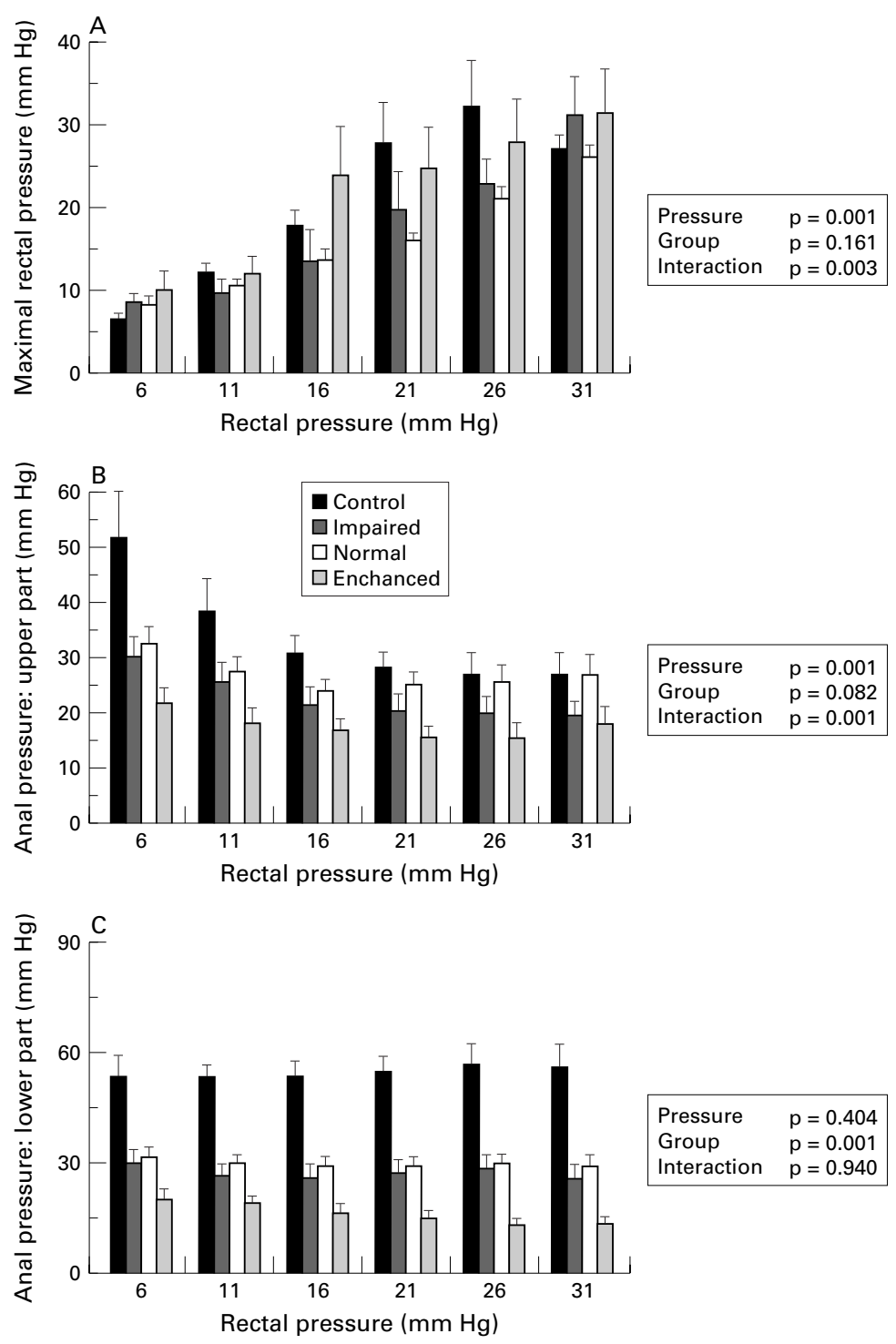

Figure 1 Rectal pressures and anal pressures recorded at both upper and lower parts as a function of rectal pressure during phasic isobaric distensions of the rectum in healthy controls and in incontinent patients with impaired, normal, or increased rectal perceptions.

were significantly decreased in incontinent groups (table 3).

(1) Maximal volumes (impaired and normal perceptions, $\mathrm{p}<0.001$ for each; enhanced perception, $\mathrm{p}=0.015)$. In incontinent patients with impaired, normal, or enhanced perception, maximal rectal vol- umes corresponded to 39,58 , and $68 \%$ of those measured in healthy subjects respectively.

(2) Rectal volumes during increasing rectal pressure (impaired and normal perceptions, $\mathrm{p}<0.001$ for each; enhanced perception, $\mathrm{p}=0.047$ ). In incontinent patients with impaired, normal, or enhanced perception, these volumes were 36,55 , and $64 \%$ of those measured in healthy subjects respectively.

(3) Rectal volumes at constant pressure (impaired and normal perceptions, $\mathrm{p}<0.001$ for each; enhanced perception, $\mathrm{p}=0.029$ ). In incontinent patients with impaired, normal or enhanced perception, these volumes were 48,63 , and $75 \%$ of those measured in healthy subjects respectively. Finally, for maximal volumes and for volume variations during increasing pressure, mean values were significantly lower in incontinents with impaired perception than in incontinents with normal ( $p=0.04$ for both parameters) or enhanced perception $(p=0.004$ and $p=0.02$ respectively). Volumes at constant pressure were significantly lower in incontinents with impaired perception than in incontinents with enhanced perception $(\mathrm{p}=0.003)$.

\section{RECTAL PERCEPTION}

Figure 3 shows rectal perception of rectal isobaric distension as a function of the pressure of distension in the four groups. Increasing pressure of distension significantly increased rectal perception score $(\mathrm{p}<0.001)$. Differences between groups were also observed (group effect, $p<0.001$ ) but these differences depended on the pressure of distension (group $\times$ pressure interaction, $\mathrm{p}<0.001$ ).

As compared with healthy subjects, patients with impaired perception had significantly lower scores at each level of distending pressure (group effect, $\mathrm{p}<0.001$; group $\times$ pressure interaction $\mathrm{p}=0.006)$. At the highest level of distending pressure $(31 \mathrm{~mm} \mathrm{Hg})$, a perception score of discomfort was reached in all healthy subjects but in only 10 of 22 patients with impaired perception. The corresponding rectal volumes recorded in these incontinents also significantly differed from those measured in healthy subjects $(120$ (18) $\mathrm{ml} v 244$ (16) $\mathrm{ml}$ respectively $\mathrm{p}<0.001)$. Similar results were observed at a perception score of moderate and definite sensation. ${ }^{4}$

Table 3 Anal and rectal adaptations to rectal isobaric distensions in control subjects and incontinent patients with impaired, normal or enhanced rectal perception

\begin{tabular}{|c|c|c|c|c|c|c|c|}
\hline & \multirow[b]{2}{*}{$\begin{array}{l}\text { Controls } \\
(n=15)\end{array}$} & \multicolumn{3}{|c|}{ Incontinent patients } & \multirow[b]{2}{*}{$\begin{array}{l}\text { Group effect } \\
\text { ( } p \text { value) }\end{array}$} & \multirow[b]{2}{*}{$\begin{array}{l}\text { Pressure effect } \\
\text { (p value) }\end{array}$} & \multirow[b]{2}{*}{$\begin{array}{l}\text { Pressure } \times \text { group } \\
\text { interaction } \\
\text { (p value) }\end{array}$} \\
\hline & & $\begin{array}{l}\text { Impaired } \\
\text { perception } \\
(n=22)\end{array}$ & $\begin{array}{l}\text { Normal } \\
\text { perception } \\
(n=61)\end{array}$ & $\begin{array}{l}\text { Enhanced } \\
\text { perception } \\
(n=14)\end{array}$ & & & \\
\hline Rectal pressure (mm Hg) & $20.5(1.7)$ & $17.6(1.6)$ & $16.0(0.6)$ & $21.7(2.1)$ & 0.161 & $0.001^{\star}$ & $0.003^{\star}$ \\
\hline \multicolumn{8}{|l|}{ Anal pressure $(\mathrm{mm} \mathrm{Hg})$} \\
\hline Upper part & $33.7(2.3)$ & $22.7(1.3)$ & $26.9(1.2)$ & $17.4(1.1)$ & 0.082 & $0.001^{\star}$ & $0.001^{\star}$ \\
\hline Lower part & $54.2(2.2)$ & $26.9(1.6)$ & $29.6(1.2)$ & $16.0(0.9)$ & $0.001^{\star}$ & 0.404 & 0.941 \\
\hline \multicolumn{8}{|l|}{ Rectal volume (ml) } \\
\hline Maximal volume & $171.5(8.5)$ & $72.0(4.3)$ & $99.3(4.2)$ & $118.5(9.5)$ & $0.001^{\star}$ & $0.001^{\star}$ & 0.393 \\
\hline Volume variation during increasing pressure & $103.0(7.5)$ & $37.8(3.2)$ & $56.7(3.2)$ & $67.0(8.1)$ & $0.001^{\star}$ & $0.001^{\star}$ & 0.414 \\
\hline Volume variation at constant pressure & $68.1(3.4)$ & $34.2(2.2)$ & $42.7(1.7)$ & $51.6(3.8)$ & $0.001^{\star}$ & $0.001^{\star}$ & 0.482 \\
\hline
\end{tabular}

Results are expressed as mean (SEM) values (all pressure steps considered) and the p values are those of the two way repeated measures analysis of variance. ${ }^{\star}$ indicates significance. 

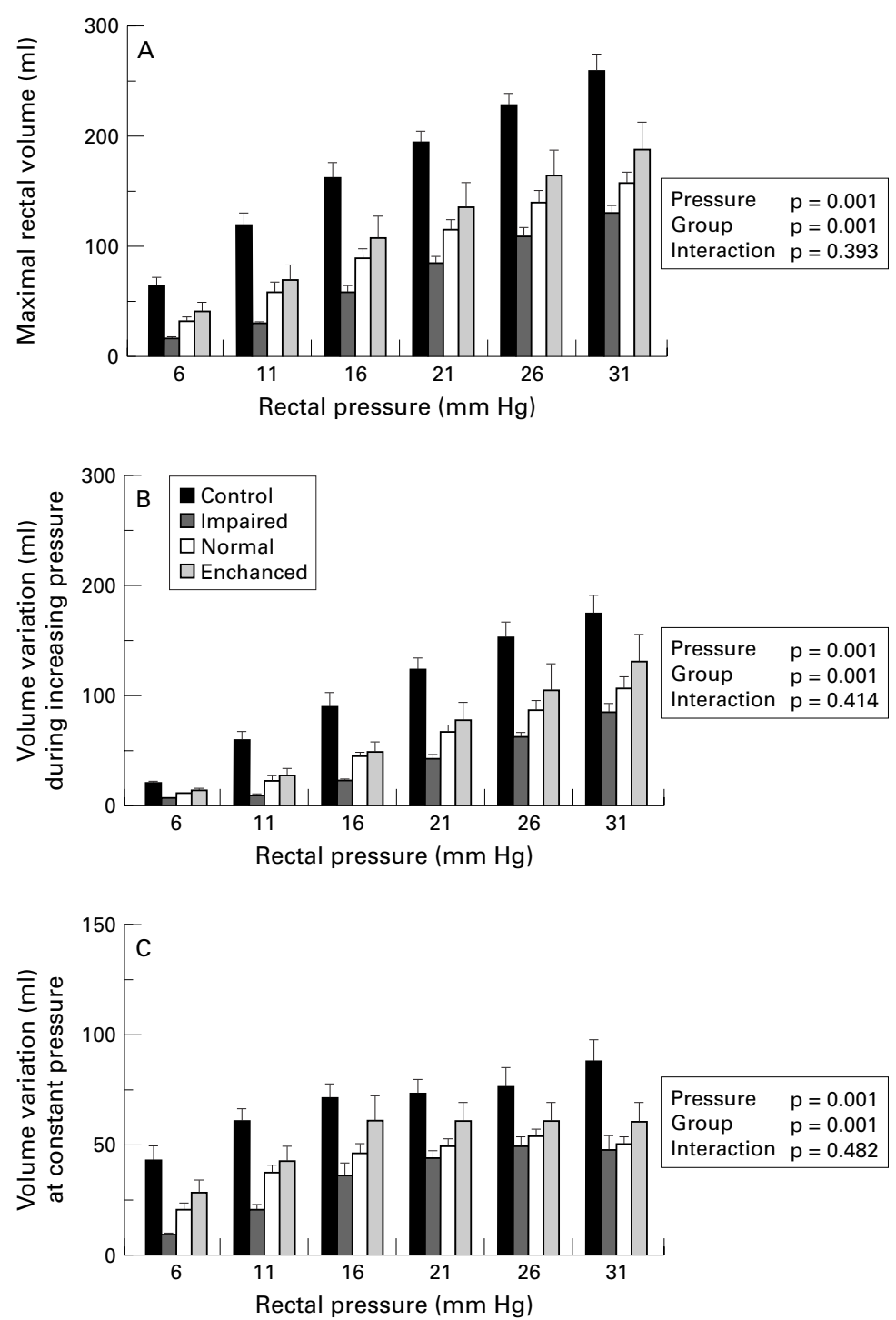

Figure 2 Rectal volumes as a function of rectal pressure during phasic isobaric distensions of the rectum in healthy controls and in incontinent patients with impaired, normal, or increased rectal perceptions. Rectal volumes were recorded at the end of each pressure plateau ( $A$; maximal rectal volume), at the end of ascending pressure variation ( $B$; volume variation during increasing pressure), and between these two points of stabilised pressure $(C$; volume variation at constant pressure).

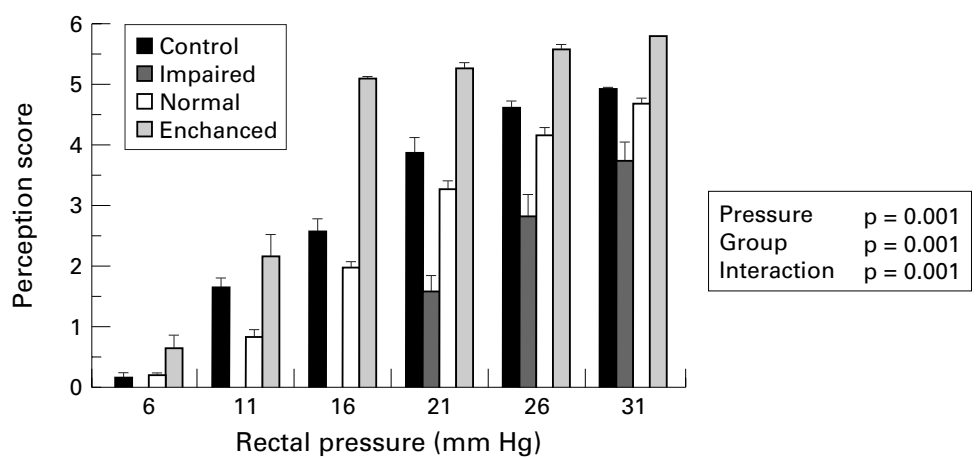

Figure 3 Rectal perception as a function of rectal pressure during phasic isobaric distensions of the rectum in healthy controls and in incontinent patients with impaired, normal, or increased rectal perceptions. Rectal perception was quantified by a score ranging from no sensation (0) to pain (6).
As compared with healthy subjects, patients with enhanced perception had significantly higher scores at each level of distending pressure (group effect, $\mathrm{p}<0.001$; group $\times$ pressure interaction, $p=0.001$ ). In this group with a sensation of discomfort, ${ }^{5}$ the corresponding rectal volumes and pressures (102 (13) $\mathrm{ml}$ and $16.0(0.02) \mathrm{mm} \mathrm{Hg})$ significantly differed from those measured in healthy subjects $(244$ (16) $\mathrm{ml}, \mathrm{p}<0.001 ; 27.6$ (1.5) $\mathrm{mm} \mathrm{Hg}, \mathrm{p}<0.001)$. Similar results were observed at a perception score of moderate and definite sensation. ${ }^{4}$

\section{Discussion}

An abnormal rectal perception was observed in one third of our incontinent group. Interestingly, problems with perception in incontinence were associated with impairment of rectal adaptation to distension. Decreased adaptation may constitute a bias or a causative factor in the analysis of impaired perception. Previous data obtained using glucagon induced relaxation were consistent with both pressure and volume dependency of gastric perception. ${ }^{18}$ Thus impairment of rectal adaptation may lead to underestimation of perception scores in isobaric distension procedures. However, how receptors in the rectal wall detect intraluminal pressure and/or volume has not been fully established. Despite a significant decrease in rectal adaptation, most patients suffering from incontinence experienced either normal or enhanced perception compared with healthy controls. Moreover, using similar models of rectal isobaric distensions in healthy subjects, rectal perception was not modified despite variations in compliance and volume induced by drugs (yohimbine excepted) or by different distension procedures. ${ }^{17} 1920$ These features favour pressure over volume dependency of rectal perception and invalidate the suggestion that lowered perception scores may reflect impaired rectal adaptation.

Hypervigilance to rectal stimuli may be defined as a descriptor discomfort used at significant lower distension pressures. ${ }^{21}$ In incontinent patients with enhanced perception, rectal adaptation did not significantly differ from that observed in incontinent patients with normal perception. Three hypotheses may be put forward to explain hypervigilance in faecal incontinence. (1) The tendency to select discomfort in the ascending series may be an anticipation response rather than a sensory discrimination. ${ }^{21}$ This phenomenon may illustrate a status of irritable bowel syndrome in these patients in whom aberrant activation of the dorsolateral prefrontal cortex has been recently shown. ${ }^{22}$ (2) Anal pressure was profoundly decreased in this subgroup; such a phenomenon may be responsible for inducing rectal hypersensitivity, which implies participation of reflex arcs and feedback mechanisms. Similar modulation of rectal sensation has been shown to follow stimulation of the sigmoid colon in patients with irritable bowel syndrome. ${ }^{23}$ (3) Finally, exquisite rectal sensitivity may be the primary event that causes the anal sphincter to relax at the slightest provocation. In fact, it has been shown that $47 \%$ of 
patients suffering from incontinence have an irritable rectum. ${ }^{5}$ All the patients in this group had abnormally weak external sphincters. Over a third of patients with a hypersensitive rectum and incontinence also had an unstable internal anal sphincter, which relaxed spontaneously under basal conditions. ${ }^{24}$

Impaired sensation during rectal distension has been reported in 10-39\% of patients with faecal incontinence. ${ }^{162526}$ Blunted perception in incontinence has often been restricted to an increase in initial volume sensation whereas constant sensation of filling and urge to defecate remain normal. ${ }^{162526}$ Moreover, recent evidence based on rectal isobaric distension or mathematical algorithms suggests that initial sensations are anal rather than rectal. ${ }^{11} 27$ According to our results, this hypothesis remains unlikely because incontinent groups differed more with respect to rectal adaptation than anal motility. Subjects with impaired perception experienced reduced rectal adaptation compared with incontinent patients with normal perception: rectal compliance curves differed between groups. In contrast, anal responses were similar in the two groups. Moreover, impaired perception was not only involved in the first perception score but in other perception scores at higher steps of distension. Because patients in our study did not experience mucosal change or surgical past history, impaired adaptation may be related to abnormal physical properties of the rectal wall, abnormal innervation, or aging process. In patients with neurogenic faecal incontinence, previous studies have shown an increase in the proportion of connective tissue in the internal anal sphincter and a decrease in both its in vivo compliance and its in vitro elasticity. ${ }^{28}{ }^{29}$ Such a process may also involve the circular layer of the rectal wall from which the internal anal sphincter arises.

Patients suffering from central nervous system disorders such as sacral trauma or agenesis are known to experience similar changes in rectal adaptation and sensation..$^{30}$ However, in our study, known neurological disorders were exclusion criteria; we cannot ascertain that impaired perception and adaptation do not represent the first manifestations of a central nervous system disorder in progress in some patients. Analysing the rectal contraction after each isobaric distension (transient decrease in rectal volume) may be useful in such a condition as it represents a spinal reflex. ${ }^{11}$ Unfortunately, it could not be identified at each pressure step and for each patient in our study groups, as already observed in healthy subjects. ${ }^{11}$

Using a similar methodology, a previous study analysed rectal adaptation in 68 normal subjects: a decrease in rectal volume and an increase in pressure threshold to produce an initial sensation were shown to correlate with increasing age. ${ }^{32}$ Our study suggests that age is an unlikely explanatory factor as it did not differ between groups.

In conclusion, abnormal perception to rectal isobaric distension is not infrequent in patients suffering from faecal incontinence. Some abnormalities may be related to overreactive anal motility in response to an irritable rectum. Other abnormalities may reflect neuropathological damage of the rectal wall.

1 Sun WM, Read NW, Miner PB. Relation between rectal sensation and anal function in normal subjects and patients with faecal incontinence. Gut 1990;31:1056-61.

2 Speakman CT, Kamm MA. Abnormal visceral autonomic innervation in neurogenic faecal incontinence. Gut 1993; $34: 215-21$.

3 Miner PB, Donnelly TC, Read NW. Investigation of mode of action of biofeedback in treatment of faecal incontinence. Dig Dis Sci 1990;35:1291-8.

4 Bielefeldt K, Enk P, Erckenbrecht JF. Sensory and motor function in the maintenance of anal incontinence. Dis Colon Rectum 1990;33:674-8.

5 Sun WM, Donnelly TC, Read NW. Utility of a combined test of anorectal manometry, electromyography, and sensation in determining the mechanism of idiopathic faecal incontinence. Gut 1992;33:807-13

6 Rao SSC, Patel RS. How useful are manometric tests of anorectal function in the management of defecation disorders? Am f Gastroenterol 1997;92:469-75.

7 Ferguson GH, Redford J, Barrett JA, et al. The appreciation of rectal distension in fecal incontinence. Dis Colon Rectum 1989;32:964-7.

8 Rasmussen O, Sorensen M, Tetzschner T, et al. Anorectal pressure gradient in patients with faecal incontinence. Dis 2;35:8-11.

9 Whitehead WE, Delvaux M. Standardization of barostat procedures for testing smooth muscle tone and sensory thresholds in the gastrointestinal tract. Dig Dis Si 1997;42: 223-41.

10 Madoff RD, Orrom WJ, Rothenberger DA, et al. Rectal compliance: a critical reappraisal. Int f Colorectal Dis 1990; 5:37-40.

11 Akervall S, Fasth S, Nordgren S, et al. Reservoir rectal and sensory function studied by graded isobaric distension in normal man. Gut 1989;30:496-502

12 Marti MC. Incontinence fécale. Epidémiologie, diagnostic et traitement. Gastroenterol Clin Biol 1992;16:T29-34.

13 Siproudhis L, Dautrème S, Ropert A, et al. How accurate is clinical examination in diagnosing and quantifying pelvirectal disorder? Dis Colon Rectum 1993;36:1030-6.

14 Hachet $T$, Caussette $M$. A multifunction and programmable computerized barostat. Gastroenterol Clin Biol 1993;17: 347-51.

15 Siproudhis L, Bellissant E, Juguet F, et al. Rectal adaptation to distension in patients with overt rectal prolapse. $\mathrm{Br} \mathcal{F}$ Surg 1998;85:1527-32.

16 Rouillon JM, Aspiroz F, Malagelada JR. Reflex changes in intestinal tone: relationship to perception. Am $\mathcal{f}$ Physiol 1991;261:280-6.

17 Siproudhis L, Bellissant E, Juguet F, et al. Effects of cholinergic agents on anorectal physiology: a dynamic study in healthy subjects. Aliment Pharmacol Ther 1998;12:747-54. determines the sensitivity of the stomach to distention. Gastroenterology 1995;108:330-6.

19 Malcolm A, Phillips SF, Camilleri M, et al. Pharmacological modulation of rectal tone alters perception of distention in humans. Am f Gastroenterol 1997;92:2073-9.

20 Siproudhis L, Bellissant E, Juguet F, et al. Effects of octreotide on anorectal physiology to isobaric distension in healthy subjects. Clin Pharmacol Ther 1998;64:424-32.

21 Naliboff BD, Munakata J, Fullerton S, et al. Evidence for two distinct perceptual alterations in irritable bowel two distinct perceptual alteration

22 Silverman DH, Munakata JA, Ennes H, et al. Regional cerebral activity in normal and pathological perception of visceral pain. Gastroenterology 1997;112:64-72.

23 Munakata J, Naliboff B, Harraf F, et al. Repetitive sigmoid stimulation induces rectal hyperalgesia in patients with irritable bowel syndrome. Gastroenterology 1997;112:55-63.

24 Sun WM, Read NW, Miner PB, et al. The role of transient internal sphincter relaxation in faecal incontinence. Int $\mathcal{f}$ Colorectal Dis 1990;5:31-6.

25 Allen ML, Orr WC, Robinson MG. Anorectal functioning in fecal incontinence. Dig Dis Sci 1988;33:36-40.

26 Meshkinpour H, Movahedi H, Welgan P. Clinical value of anorectal manometry index in neurogenic fecal incontinence. Dis Colon Rectum 1997;40:457-61.

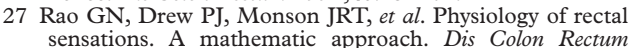
1997;40:298-306.

28 Swash M, Gray A, Lubowski DZ, et al. Ultrastructural changes in internal anal sphincter in neurogenic faecal incontinence. Gut 1988;29:1692-8.

29 Speakman CTM, Hoyle CHV, Kamm MA, et al. Abnormal internal anal sphincter fibrosis and elasticity in fecal incontinence. Dis Colon Rectum 1995;38:407-10.

$30 \mathrm{McD}$ onagh R, Sun WM, Thomas DG, et al. Anorectal function in patients with complete supraconal spinal cord lesions. Gut 1992;33:1532-38.

31 Morera C, Nurko S. Influence of sacral roots on anorectal function. A study of patients with isolated sacral agenesis. [abstract] Gastroenterology 1998;104:A806.

32 Akervall S, Nordgren S, Fasth S, et al. The effects of age, gender, and parity on rectoanal functions in adults. Scand $\mathcal{f}$ Gastroenterol 1990;25:1247-56. 